\title{
Improvement of left atrial function and left atrial reverse remodeling after minimally invasive radiofrequency ablation evaluated by 2-dimensional speckle tracking echocardiography
}

\author{
Mark La Meir, MD, ${ }^{\mathrm{a}, \mathrm{b}}$ Sandro Gelsomino, MD, PhD, ${ }^{\mathrm{a}, \mathrm{c}}$ Fabiana Lucà, MD, ${ }^{\mathrm{a}, \mathrm{c}}$ Laurant Pison, MD, ${ }^{\mathrm{d}}$ \\ Carmelo Massimiliano Rao, MD, ${ }^{\mathrm{a}, \mathrm{c}}$ Francis Wellens, MD, PhD, ${ }^{\mathrm{b}}$ and Jos G. Maessen, MD, PhD ${ }^{\mathrm{a}}$
}

\begin{abstract}
Objective: The present study was aimed at demonstrating the beneficial effect of minimally invasive radiofrequency surgical ablation on left atrial remodeling using 2-dimensional speckle-tracking echocardiography.

Methods: The study population consisted of 33 patients (mean age, $64.6 \pm 6.9$ years; $84.8 \%$ men) with paroxysmal lone atrial fibrillation undergoing minimally invasive radiofrequency surgical ablation at our institution (University Hospital Maastricht, Maastricht, The Netherlands) from 2007 to 2011. The control group included 20 age- and gender-matched healthy adults. The left atrial peak systolic strain, peak strain rate, peak early diastolic strain rate, and peak negative strain rate were measured. Left atrial reverse remodeling was defined as a reduction in the left atrial volume index of $15 \%$ or greater.
\end{abstract}

Results: The peak systolic strain was lower in patients with atrial fibrillation than in the controls $(P<.001)$. It had increased significantly at 3 months $(P<.001)$ and 12 months $(P=.01)$ after surgery. Similarly, the peak strain rate $(P<.001)$ was lower in patients with atrial fibrillation but had increased 3 months $(P=.004)$ and 12 months $(P=.001)$ after surgery. Finally, the peak early diastolic strain rate $(P<.001)$ and peak negative strain rate $(P<.001)$ were less negative at baseline compared with the rates in the controls. Both indexes had improved significantly at the follow-up examinations ( 3 months, $P=.008$ and $P=.02 ; 12$ months, both $P=.01$ ). Left atrial reverse remodeling occurred in $60.6 \%$ of patients at 3 months and $72.7 \%$ at 12 months postoperatively.

Conclusions: Minimally invasive radiofrequency ablation resulted in significant left atrial reverse remodeling and significant improvement in left atrial compliance and function after restoration of sinus rhythm, as demonstrated by 2-dimensional speckle-tracking echocardiography analysis. Our findings need to be confirmed by additional and larger prospective studies. (J Thorac Cardiovasc Surg 2013;146:72-7)

Two-dimensional speckle-tracking echocardiography (2D-STE) is a non-Doppler-based technique that has been used recently to evaluate dynamic left atrial (LA) function. ${ }^{1}$ 2D-STE has been demonstrated to be an easy and reproducible tool for the assessment of atrial mechanics in atrial fibrillation $(\mathrm{AF})^{2}$ and to reveal findings that are predictors of stroke risk and cardiovascular outcomes in patients with $\mathrm{AF}^{3}$

Electrical remodeling (ie, shortening of atrial refractoriness), structural remodeling (ie, alterations in atrial collagen content and atrial geometry), and contractile remodeling (ie, loss of contractility) are hallmarks of the

\footnotetext{
From the Department of Cardiothoracic Surgery, ${ }^{a}$ University Hospital Maastricht, Maastricht, The Netherlands; Department Cardiovascular and Thoracic Surgery, ${ }^{\mathrm{b}}$ University Hospital, Brussels, Belgium; Experimental Surgery Unit, ${ }^{\mathrm{c}}$ Department of Heart and Vessels, Careggi Hospital, Florence, Italy; and Department of Cardiology, ${ }^{\mathrm{d}}$ University Hospital Maastricht, Maastricht, The Netherlands.

Disclosures: Authors have nothing to disclose with regard to commercial support.

M.L.M. and S.G. contributed equally to the report.

Received for publication June 10, 2011; revisions received April 16, 2012; accepted for publication May 17, 2012; available ahead of print June 19, 2012.

Address for reprints: Sandro Gelsomino, MD, PhD, Experimental Surgery Unit,

Department of Heart and Vessels, Careggi Hospital, Viale Morgagni 85, Florence

50134, Italy (E-mail: sandro.gelsomino@libero.it).

$0022-5223 / \$ 36.00$

Copyright (c) 2013 by The American Association for Thoracic Surgery

http://dx.doi.org/10.1016/j.jtcvs.2012.05.068
}

electrophysiologic and cellular changes occurring in $\mathrm{AF}^{4-6}$ All these changes are partly reversible, with recovery of function, morphology, and, to some extent, the electrophysiologic properties of the LA tissue (LA reverse remodeling [LARR]) ${ }^{7}$ Reverse remodeling has been shown with restoration of sinus rhythm after cardioversion. ${ }^{8}$ In addition, LARR has been demonstrated to occur in a significant number of patients after successful catheter ablation for AF, and it has been shown that the baseline LA strain was an independent predictor of LARR after this procedure. ${ }^{9,10}$

Nonetheless, little information exists about LA function and LA strain after AF surgical ablation. To the best of our knowledge, no data have been published on this topic regarding minimally invasive procedures.

Therefore, the present study was aimed at demonstrating the beneficial effect of minimally invasive radiofrequency surgical ablation on LA function after restoration of sinus rhythm using 2D-STE.

\section{METHODS \\ Study Population}

The study protocol followed the World Medical Association guidelines concerning the ethical principles for medical research involving human 


$$
\begin{aligned}
& \text { Abbreviations and Acronyms } \\
& \begin{array}{ll}
\text { AAD } & =\text { antiarrhythmic drugs } \\
\text { AF } & =\text { atrial fibrillation } \\
\text { AP } & =\text { anteroposterior } \\
2 \mathrm{D}- & =\text {-dimensional speckle-tracking } \\
\text { STE } & \text { echocardiography } \\
\varepsilon_{\mathrm{P}} & =\text { peak systolic strain } \\
\mathrm{IQR} & =\text { interquartile range } \\
\mathrm{LA} & =\text { left atrial } \\
\mathrm{LAA} & =\text { left atrial appendage } \\
\text { LARR } & \text { left atrial reverse remodeling } \\
\text { LV } & =\text { left ventricular } \\
\text { SI } & =\text { superoinferior } \\
\mathrm{SR}_{\mathrm{A}} & =\text { peak negative strain rate } \\
\mathrm{SR}_{\mathrm{P}} & =\text { peak strain rate }
\end{array}
\end{aligned}
$$

subjects, and the institutional ethics board approved the study. All patients gave their informed consent.

Patients were included in our study according to the following inclusion criteria: paroxysmal AF treated successfully by radiofrequency bipolar surgical ablation for lone AF (LAF) and a history ( $>6$ months) of paroxysmal recurrent $\mathrm{AF}$ with symptoms but in stable sinus rhythm in the 48 hours preceding the ablation therapy to perform dedicated echocardiography. The exclusion criteria were previous ablation procedures; the presence of intracardiac thrombi on the transesophageal echocardiogram; a patent foramen ovale or atrial septal defect; a "giant" left atrium (diameter, $>65 \mathrm{~mm}$ ); coronary artery disease; and previous pulmonary or cardiac surgery.

LAF was defined according to the American College of Cardiology/ American Heart Association/European Society of Cardiology guidelines ${ }^{11}$ and updated European Society of Cardiology guidelines were used to distinguish the AF type and to score the AF-related symptoms (European Heart Rhythm Association score). ${ }^{12}$

Of 72 patients undergoing minimally invasive radiofrequency surgical ablation at our institution (Department of Cardiothoracic Surgery, University Hospital Maastricht, Maastricht, The Netherlands) from 2007 to 2011, 33 met the inclusion criteria and were included in the present study. The patient characteristics are listed in Table 1.

The control group included 20 age- and gender-matched healthy adults without cardiovascular disease or a history of cardiovascular disease or cardiovascular risk factors and who did not use cardiovascular medication as a reference for the LA atrial function assessment using echocardiography.

\section{Surgery}

The indication for surgery was determined by the Heart Rhythm Society/ European Heart Rhythm Association/European Cardiac Arrhythmia Society guidelines. ${ }^{13}$ All operations were performed by the same cardiac surgeon (M.L.M). The chest was entered in the second, fourth, and sixth interspaces using a 5-, 12-, and 12-mm port, respectively. Thoracoscopy of the right side was done first, followed by the left side. The pericardium was opened anterior to the phrenic nerve on the right and posterior to the phrenic nerve on the left. The technique was performed as originally described by Yilmaz and colleagues. ${ }^{14}$ The rhythm was determined by placing a bipolar pen probe (Atricure, Westchester, Ohio) on the left atrium, and recordings were made with a physiologic recorder. ${ }^{15}$ The autonomic ganglia were identified using high-frequency stimulation to detect a vagal response at 20 predetermined epicardial sites around the pulmonary vein antra.

Ablation of the right and left pulmonary veins was performed using a bipolar radiofrequency clamp (Atricure). With the clamp placed on the antrum of the pulmonary veins, 3 to 6 ablations were performed (mean,
$3.8 \pm 0.9$ ). The endpoint for pulmonary vein ablation was a complete entrance and exit block into and from the pulmonary veins. Entrance block was defined as failure to capture the pulmonary veins during pacing from the left atrium with $7.5 \mathrm{~V}$ and a 1.5 -ms pulse width. Exit block was defined as failure to capture the left atrium when pacing from the pulmonary veins distal to the radiofrequency lesions with $7.5 \mathrm{~V}$ and a $1.5-\mathrm{ms}$ pulse width. A proprietary algorithm terminated the radiofrequency energy (maximum, $28 \mathrm{~W}$ ) after impedance changes indicated transmural injury. In 19 patients $(57.5 \%)$, the entrance and exit blocks were checked endocardially by the electrophysiologist through a catheter (Lasso Catheter, Biosense Webster, Diamond Bar, Calif) placed at the ostium of the pulmonary veins to assess the presence of pulmonary vein potentials.

Ganglionated plexi mapping was performed by placing the bipolar pen at each site and stimulating with an $18-\mathrm{mV}, 1.5-\mathrm{ms}$ pulse width impulse at 1000 pulses/min from a temporary external pacemaker. A positive response to ganglionated plexi stimulation was defined as prolongation of the sinus cycle or mean AF cycle length by $50 \%$ or more. Bipolar radiofrequency energy at $15 \mathrm{~W}$ was delivered through the bipolar pen. The endpoint for ganglionated plexi ablation was the elimination of a vagal response to stimulation.

Connecting lesions, the roof and inferior lines, were created using the Coolrail and/or the Max5 Pen (Coolrail, Atricure). The lesions were tested after completion of both lines by pacing inside the isolated posterior left atrium and confirming the exit block.

Left atrial appendage (LAA) exclusion or closure was performed under transesophageal echocardiographic guidance in patients with a $\mathrm{CHADS}_{2}$ (cardiac failure, hypertension, age, diabetes, previous stroke or transient ischemic attack) score of 1 or more, ${ }^{16}$ in the presence of a rapid firing coming from the LAA and when it was deemed safe. The LAA was excluded in 4 patients $(12.1 \%)$ using a stapler (EndoGIA, Covidien, Norwalk, Conn). In 6 patients $(18.1 \%)$, it was closed using a clip (Atricure). The absence of flow was confirmed by intraoperative transesophageal echocardiography.

\section{Echocardiographic Assessments}

Echocardiography was performed preoperatively and at 3 and 12 months postoperatively using a commercially available echocardiographic system (Philips iE33; Philips Medical Systems, Eindhoven, The Netherlands). All parameters were analyzed by 2 experienced echocardiographers (F.L. and C.M.R) using Xcelera software (Philips Medical Systems). The left ventricular ejection fraction was assessed using the biapical Simpson disk method. ${ }^{17}$

In the parasternal long-axis views, the LA maximum anteroposterior (AP) diameter was measured.

The LA superoinferior (SI) diameter was measured from the mitral annular plane to the posterior wall of the left atrium in the apical 4-chamber view. In the apical 4-chamber view, the LA maximum volume, at the end of left ventricular (LV) systole, just before the opening of the mitral valve and LA minimum volume at the end of LV diastole, just after the closure of the mitral valve, were measured. ${ }^{3}$ The LA emptying fraction was calculated as follows: ([LA maximum volume - LA minimum volume]/LA maximum volume) $\times 100$. The LA maximum volume was also measured using the biplane area-length method ${ }^{18}$ and indexed to the body surface area (LA volume index [LAVI]]). The LARR was defined as a reduction in the LAVI of $15 \%$ or more ${ }^{10}$ Responders were defined as those patients with a $15 \%$ or greater reduction in the LAVI and nonresponders as those without such a reduction.

Pulsed-wave Doppler at the tips of the mitral valve leaflets allowed us to measure the early (E) and late (A) diastolic filling velocities, diastolic E/A ratio, and $\mathrm{E}$ deceleration time. For tissue Doppler imaging (TDI), the peak early diastolic tissue velocity (E) and peak late diastolic velocity $\left(\mathrm{A}^{\prime}\right)$ were recorded from a 4-chamber view at the lateral and septal border of the mitral annulus. The septal and lateral measures were averaged according to published guidelines. ${ }^{19}$

We used $\mathrm{A}^{\prime}$ as a reproducible measure of LA function. ${ }^{20}$ Finally, the $\mathrm{E} / \mathrm{E}^{\prime}$ ratio was calculated and used as a reliable index of the LV filling pressure. $^{21}$ 
TABLE 1. Preoperative data $(n=33)$

\begin{tabular}{lc}
\hline \multicolumn{1}{c}{ Variable } & Value \\
\hline Age $(\mathrm{y})$ & $64.6 \pm 6.9$ \\
Gender & \\
$\quad$ Male & $28(84.8)$ \\
Female & $5(15.2)$ \\
BMI $\left(\mathrm{kg} / \mathrm{m}^{2}\right)$ & $27.9 \pm 3.3$ \\
Hypertension & $18(54.5)$ \\
Prevalence of AF & \\
$\quad$ Median & 20.8 \\
IQR & $16.5-23.6$ \\
EHRA score & \\
$\quad$ Median & 3 \\
$\quad$ IQR & $3-4$ \\
Duration of preoperative AF (y) & $6.3 \pm 2.1$ \\
Antiarrhythmic drugs & \\
Amiodaron & $2(6.0)$ \\
Flecainide & $20(60.6)$ \\
Propaphenon & $7(21.2)$ \\
Ibutilide & $1(3.0)$ \\
Electrical cardioversion & $17(51.5)$ \\
Sodium warfarin & $33(100)$ \\
LVEF & $60.1 \pm 7.1$ \\
\hline
\end{tabular}

Data are presented as mean \pm standard deviation, median and IQR, or, for discrete data, numbers (percentages). $A F$, Atrial fibrillation; $B M I$, body mass index; $E H R A$, European Heart Rhythm Association; $L V E F$, left ventricular ejection fraction; $I Q R$, interquartile range.

\section{Speckle Tracking}

Longitudinal LA strain was computed using speckle-tracking echocardiography (2-dimensional cardiac performance analysis; TomTec Imaging Systems, Munich, Germany).

The data from a total of 12 LA segments (annular, mid, and superior segments along the septal, lateral, anterior, and inferior LA walls using apical 4-chamber and 2-chamber images) were averaged to determine the global LA peak systolic strain $\left(\varepsilon_{\mathrm{P}}\right)$ during $\mathrm{LV}$ ejection (LA reservoir phase). The peak strain rate $\left(\mathrm{SR}_{\mathrm{P}}\right)$ was measured during $\mathrm{LV}$ ejection (LA reservoir phase). The peak early diastolic strain rate $\left(\mathrm{SR}_{\mathrm{E}}\right)$ was measured during LV early diastole (LA conduit phase), and peak negative strain rate $\left(\mathrm{SR}_{\mathrm{A}}\right)$ was measured during $\mathrm{LV}$ diastole occurring after the $\mathrm{P}$ wave (active contraction phase).

Assessment of LV strain was regarded as suboptimal when either speckle tracking could not be obtained for at least 4 of the 6 myocardial segments in each view or a theoretically unacceptable value or values were obtained.

\section{Primary Endpoint and Assessment of AF}

The primary efficacy endpoint was freedom from AF and atrial flutter/ tachycardia off antiarrhythmic drugs (AAD) after the blanking period. ${ }^{13,22}$

Patients underwent 7-day Holter monitoring at 3 and 12 months. ${ }^{23}$ Monitoring was performed with an external loop recorder (Del Mar Reynolds, Spacelabs Healthcare, Issaquah, Wash) and analyzed with Lifescreen Software (Del Mar Reynolds, Spacelabs Healthcare, Issaquah, Wash). For analysis, 3 rhythms were considered to indicate postoperative AF: AF, atrial flutter, or atrial tachycardia lasting more than 30 seconds after a 3-month blanking period.

\section{Anticoagulation and Antiarrhythmic Therapy}

$\mathrm{AAD}$ were given postoperatively and were discontinued 3 months after surgery if the patients appeared to be free of AF. Electrical cardioversion was not attempted for patients who remained in AF after the surgical procedure and was reserved for patients who were still in AF after 6 months. Warfarin was administered on postoperative day 1 with an international normalized ratio target of 2.5 and stopped after 3 months if 2 subsequent 24-hour Holter recordings showed a sinus rhythm or patients had a low thromboembolic risk and a $\mathrm{CHADS}_{2}$ (cardiac failure, hypertension, age, diabetes, previous stroke or transient ischemic attack) score of less than $2 .^{12}$

\section{Statistical Analysis}

Parametric values are expressed as the mean \pm standard deviation, nonparametric values as the median and interquartile range (IQR), and categorical variables as percentages. Normally distributed variables were compared using a paired $t$-test, and the Fisher and McNemar test was used to compare unpaired and paired categorical data, respectively.

Echocardiographic variables over time were analyzed using analysis of variance repeated measures followed by Tukey's post hoc test to detect differences at different study points.

Interobserver and intraobserver variability were examined using Pearson bivariate correlation. The intraobserver and interobserver correlations were as follows: $\varepsilon_{\mathrm{P}}, r=0.90(P<.001)$ and $r=0.77(P=.002)$; $\mathrm{SR}_{\mathrm{P}}$, $r=0.89(P<.001)$ and $r=0.80(P=.001) ; \mathrm{SR}_{\mathrm{E}}, r=0.92(P<.001)$ and $r=0.70(P=.01) ; \mathrm{SR}_{\mathrm{A}}, r=0.88(P<.001)$ and $r=0.75(P=.006)$.

Analyses were performed using SPSS, release 12.0 (SPSS, Chicago, Ill).

\section{RESULTS \\ Clinical Results}

No patient died within the first 30 days postoperatively. No pulmonary vein injury, mortality, stroke, or reoperation for bleeding was recorded. All the procedures could be completed as planned without any conversion to sternotomy. No blood transfusion was required. The median intensive care unit stay was 5.7 hours (IQR, 3.7-11.6) and the median in-hospital length of stay was 6 days (IQR, 5-7).

No patient died during follow-up. The European Heart Rhythm Association score improved significantly from baseline (median, 1; IQR, 1-2; $P<.001$ ). All patients were in sinus rhythm and off AAD at 3 and 12 months of follow-up. No major thromboembolic events were detected during the follow-up period, and no patient was taking warfarin. Finally, no patient underwent electrical cardioversion.

\section{LA Reverse Remodeling}

The baseline morphologic analysis (Table 2) revealed a significant LA enlargement in the patients with $\mathrm{AF}$

TABLE 2. Left atrial remodeling and reverse remodeling $(\mathbf{n}=33)$

\begin{tabular}{|c|c|c|c|c|}
\hline \multirow[b]{2}{*}{ Variable } & \multirow{2}{*}{$\begin{array}{c}\text { Control } \\
\text { group }\end{array}$} & \multicolumn{3}{|c|}{ Patients with AF } \\
\hline & & Baseline & 3 months & 12 months \\
\hline LAVI $\left(\mathrm{mL} / \mathrm{m}^{2}\right)$ & $32 \pm 7$ & $42 \pm 12 *$ & $37 \pm 10^{*}, \dagger$ & $34 \pm 9^{*}, \dagger$ \\
\hline $\mathrm{LA}_{\operatorname{Max}}\left(\mathrm{mL} / \mathrm{m}^{2}\right)$ & $35 \pm 14$ & $52 \pm 25^{*}$ & $46 \pm 20^{*}, \dagger$ & $39 \pm 16^{*}, \ddagger$ \\
\hline $\mathrm{LA}_{\mathrm{Min}}\left(\mathrm{mL} / \mathrm{m}^{2}\right)$ & $12 \pm 8$ & $32 \pm 18^{*}$ & $26 \pm 10^{*}, \dagger$ & $21 \pm 11^{*}$, \\
\hline LA AP (cm) & $3.1 \pm 0.4$ & $4.2 \pm 0.5^{*}$ & $3.8 \pm 0.4^{*}, \dagger$ & $3.4 \pm 0.4^{*}, \ddagger$ \\
\hline LA SI $(\mathrm{cm})$ & $4.3 \pm 0.6$ & $6.3 \pm 0.7 *$ & $5.7 \pm 0.5^{*}, \dagger$ & $5.3 \pm 0.5^{*}, \dagger$ \\
\hline
\end{tabular}


TABLE 3. Left atrial function and strain analysis

\begin{tabular}{lcrrr}
\hline & & \multicolumn{3}{c}{ Patients with AF } \\
\cline { 3 - 5 } Variable & Controls & Baseline & 3 months & 12 months \\
\hline $\mathrm{LA}_{\mathrm{EF}}(\%)$ & $65 \pm 13$ & $38 \pm 14^{*}$ & $42 \pm 16^{*}, \dagger$ & $49 \pm 18^{*}, \ddagger$ \\
$\varepsilon_{\mathrm{P}}(\%)$ & $35.8 \pm 15$ & $17.9 \pm 9.5^{*}$ & $23.6 \pm 9.8^{*}, \dagger$ & $28.7 \pm 15.7^{*}, \ddagger$ \\
$\mathrm{SR}_{\mathrm{P}}\left(\mathrm{s}^{-1}\right)$ & $1.42 \pm 0.70$ & $0.78 \pm 0.33^{*}$ & $0.96 \pm 0.46^{*}, \dagger$ & $1.23 \pm 0.55^{*}, \ddagger$ \\
$\mathrm{SR}_{\mathrm{E}}\left(\mathrm{s}^{-1}\right)$ & $-1.75 \pm 0.83$ & $-1.02 \pm 0.53^{*}$ & $-1.23 \pm 0.66^{*}, \dagger$ & $-1.47 \pm 0.66^{*}, \ddagger$ \\
$\mathrm{SR}_{\mathrm{A}}\left(\mathrm{s}^{-1}\right)$ & $-2.03 \pm 0.5$ & $-1.41 \pm 0.67^{*}$ & $-1.63 \pm 0.76^{*}, \dagger$ & $-1.87 \pm 0.86^{*}, \ddagger$ \\
\hline
\end{tabular}

$A F$, Atrial fibrillation; $\varepsilon_{P}$, peak systolic strain; $L A_{E F}$, left atrial emptying fraction; $S R_{A}$, peak late diastolic strain rate; $S R_{E}$, peak early diastolic strain rate; $S R_{P}$, peak systolic strain rate. *Significance vs controls. †Significance vs baseline. †Significance vs 3 months.

compared with the controls (LA AP diameter, $P=.006$; LA SI diameter, $P=.001)$. This enlargement was accompanied by an increase in the maximum LA volume $(P=.001)$, minimum LA volume $(P<.001)$, and biplane LAVI $(P=.02)$.

The LA diameters had decreased significantly at 3 months (LA AP diameter, $P=.04$; LA SI diameter, $P=.004$ ) and 12 months (both, $P=.04$ ). The maximum LA volume $(P=.02$ and $P=.03)$, minimum LA volume $(P=.02$ and $P=.03)$, and biplane LAVI $(P=.03$ and $P=.04)$ was significantly reduced at 3 and 12 months postoperatively, respectively.

According to the cutoff value ( $\geq 15 \%$ decrease in LAVI), LA reverse remodeling occurred in $60.6 \%$ of patients $(\mathrm{n}=20)$ at 3 months and $72.7 \%(\mathrm{n}=24)$ at 12 months postoperatively $(P=.31)$. At 3 months, the LAVI in nonresponders had decreased by $10 \%$ or more in 7 patients $(21.2 \%)$, less than $10 \%$ in $3(9.1 \%)$, and was relatively stable $( \pm 1 \%)$ in 3 patients $(9.1 \%)$. At 12 months, the LAVI in nonresponders had decreased by $10 \%$ or more in 6 patients $(18.2 \%)$, less than $10 \%$ in $2(6.1 \%)$, and was relatively stable $( \pm 1 \%)$ in $1(3.0 \%)$.

\section{LA Function and Strain Analysis}

Compared with the control group, the LA emptying fraction was significantly lower at baseline $(P<.001$; Table 3$)$. It had increased significantly at $3(P=.04)$ and $12(P=.02)$ months.

Of the 1428 segments from the 33 patients (baseline and 3 - and 12-month follow-up points) and 20 controls, analysis of regional strain was feasible in 1313 segments $(91.9 \%)$.

The global $\varepsilon_{\mathrm{P}}$ was reduced in patients with $\mathrm{AF}$ compared with that in the controls $(P<.001$; Table 3$)$. It increased significantly at 3 months $(P<.001)$ and 12 months $(P=.01)$. Similarly, the $\mathrm{SR}_{\mathrm{P}}(P<.001)$ was lower in patients with AF but had increased after surgery at 3 $(P=.004)$ and $12(P=.001)$ months. Finally, the $\mathrm{SR}_{\mathrm{E}}$ $(P<.001)$ and $\mathrm{SR}_{\mathrm{A}}(P<.001)$ were less negative at baseline compared with those in the controls. Both indexes had improved significantly at the follow-up examinations (3 months, $P=.008$ and $P=.02 ; 12$ months, both $P=.01$ ).

\section{Pulsed-Wave Doppler and TDI}

The peak E-wave velocity, E-wave deceleration time, and $\mathrm{E} / \mathrm{A}$ ratio (Table 4) in the patients with $\mathrm{AF}$ were not significantly different from those of the controls at baseline. Also, none of these indexes varied during the follow-up period. In contrast, the A-wave velocity was lower in the patients than in the controls at baseline $(P=.03)$ and had increased significantly at $3(P=.03)$ and $12(P=.04)$ months.

The baseline TDI late diastolic filling velocity (A') was lower than that in the controls $(P>.001)$ and had increased at 3 months $(P=.01)$ and 12 months $(P=.008)$. Finally, no difference was detected at baseline in the $\mathrm{E}^{\prime}$ wave and $\mathrm{E} / \mathrm{E}^{\prime}$ between the controls and patients with AF. These indexes did not show any significant modification during the follow-up period.

\section{DISCUSSION}

In recent years, owing to the development of a variety of ablative energy sources and increasing knowledge about the pathophysiology of AF and the development of new ablation devices, minimally invasive surgical ablation of LAF has been performed with satisfactory results. ${ }^{24}$

Atrial structural remodeling, with altered LA compliance, LA enlargement, and impaired contractility, is a hallmark of AF. Reverse remodeling and recovery of atrial function are considered important targets of any AF treatment. ${ }^{10}$ LARR has been demonstrated with drug therapy, after restoration of sinus rhythm with cardioversion and after successful catheter ablation for AF. ${ }^{10}$ Nonetheless, reverse remodeling and atrial function in response to successful surgical AF ablation have been poorly

TABLE 4. Pulsed-wave Doppler and tissue Doppler imaging

\begin{tabular}{|c|c|c|c|c|}
\hline \multirow[b]{2}{*}{ Variable } & \multirow[b]{2}{*}{ Controls } & \multicolumn{3}{|c|}{ Patients with AF } \\
\hline & & Baseline & 3 months & 12 months \\
\hline $\mathrm{E}(\mathrm{cm} / \mathrm{s})$ & $86.3 \pm 10.7$ & $82.0 \pm 9.2$ & $85.6 \pm 15.9$ & $86.9 \pm 16.1$ \\
\hline $\mathrm{A}(\mathrm{cm} / \mathrm{s})$ & $65.5 \pm 7.2$ & $56.6 \pm 5.3^{*}$ & $60.8 \pm 8.9^{*}, \dagger$ & $63.7 \pm 12.1$ \\
\hline $\mathrm{E} / \mathrm{A}$ & $1.38 \pm 0.33$ & $1.40 \pm 0.35$ & $1.40 \pm 0.35$ & $1.34 \pm 0.37$ \\
\hline DT (ms) & $206 \pm 41$ & $202 \pm 37$ & $200 \pm 34$ & $202 \pm 39$ \\
\hline $\mathrm{E}^{\prime}$ & $11.2 \pm 2.7$ & $10.8 \pm 2.2$ & $11.1 \pm 2.0$ & $11.4 \pm 2.1$ \\
\hline $\mathrm{E} / \mathrm{E}^{\prime}$ & $8.1 \pm 1.6$ & $7.8 \pm 1.7$ & $7.7 \pm 1.6$ & $7.7 \pm 1.5$ \\
\hline $\mathrm{A}^{\prime}$ & $10.5 \pm 3.0$ & $7.0 \pm 2.1 *$ & $8.2 \pm 2.9^{*}, \dagger$ & $9.4 \pm 2.0 *, \ddagger$ \\
\hline
\end{tabular}


investigated, ${ }^{25}$ and little is known about the morphologic and functional changes after minimally invasive AF surgical ablation. It was for this reason we conducted the present study to evaluate LA function after restoration of sinus rhythm using minimally invasive methods.

Currently, no standardization is available for the measurement of LA function. Transmitral flow velocity with pulsed Doppler imaging will show the flow velocity resulting from atrial contraction. This can be used to measure the atrial force; however, the A wave is highly dependent on loading conditions and diastolic function. ${ }^{3}$ TDI has the advantage of increased spatial resolution and the ability to evaluate multiple segments in a single view, and the TDI $\mathrm{A}^{\prime}$ wave is a reproducible measure of LA function. ${ }^{21} \mathrm{An}$ other method to assess atrial function is to measure the LA emptying fraction. In sinus rhythm, atrial emptying includes both passive and active phases. In AF, there is only a passive phase; hence, the term "emptying fraction" rather than "ejection fraction." 3 Preoperative LA emptying fraction was shown to be a powerful predictor of successful MAZE procedure. ${ }^{26}$

Myocardial mechanics by strain imaging, which is widely used to asses ventricular function, has recently been used to evaluate atrial function. ${ }^{1}$ Nonetheless, strain determined using Doppler techniques has inherent limitations caused by angle dependency and the influence of loading conditions.

2D-STE is a novel non-Doppler-based method for the angle-independent and objective quantification of myocardial deformation that has recently been introduced to evaluate LA function ${ }^{1}$ to overcome many of the limitations of Doppler-based methods. ${ }^{2,3}$

To our knowledge, this is the first study that substantiates the changes in LA structure and function after minimally invasive surgery for LAF using 2D-STE.

In our experience, patients preoperatively showed significant impairment in LA compliance (reservoir function) estimated by the global $\varepsilon_{\mathrm{P}}$ and $\mathrm{SR}_{\mathrm{P}}$.

Kuppahally and colleagues ${ }^{3}$ found that LA fibrosis detected by 3-dimensional delayed-enhancement magnetic resonance imaging had significant correlation with systolic strain and strain rate. Tops and colleagues ${ }^{10}$ demonstrated that the LA strain at baseline was an independent predictor of LA reverse remodeling. Although the exact mechanism remains to be elucidated, the impairment in atrial compliance represented plays an important role in the ability to reverse LA enlargement and to maintain sinus rhythm during the follow-up period. ${ }^{10}$ Both $\varepsilon_{\mathrm{P}}$ and $\mathrm{SR}_{\mathrm{P}}$ increased significantly after surgery, suggesting that this postoperative improvement in atrial compliance might have resulted from still reversible LA functional changes in these patients. The improvement in atrial compliance is also demonstrated by a postoperative significant increase in the LA emptying fraction.
Furthermore, the baseline LA conduit function (during LV passive filling) was also significantly altered, as shown by the $\mathrm{SR}_{\mathrm{E}}$ values. We observed a significant improvement in the conduit phase, as demonstrated by the $\mathrm{SR}_{\mathrm{E}}$, values, which was also maintained also at the late follow-up examination.

Moreover, we showed an improvement in LA function after restoration of sinus rhythm reflected either by a mechanical reverse remodeling process or by enhancement in LA function. A traditional and widely used method of assessing structural remodeling is to measure LA AP diameter. Nonetheless, the utility of this approach is limited, because the left atrium can enlarge asymmetrically. Hence, we examined the LA SI diameter, which correlated more strongly with LA strain than with the LA AP diameter. ${ }^{3}$ However, we found a significant reduction in both diameters at the 3- and 12-month follow-up examinations.

The increment in LA volume is 1 of the most important structural pathologic changes in AF. The stretching of the LA myocites increases the intercellular matrix, collagen production, and fibrosis. The LA volume showed a strong correlation with the extent of fibrosis on 3-dimensional delayed-enhancement magnetic resonance imaging, ${ }^{3,7}$ and it was associated with greater mortality in patients with $\mathrm{AF}^{2}$ Thus, reverse remodeling of the left atrium is considered an important target of AF treatment. In our experience, using the cutoff value $(\geq 15 \%$ decrease in LAVI), LA reverse remodeling occurred in $60.6 \%$ of patients at 3 months and $72.7 \%$ at 12 months postoperatively.

Finally, an important finding in our study was the postoperative significant improvement in LA pump function demonstrated by an increase, at 3 and 12 months, of $\mathrm{SR}_{\mathrm{A}}$ that was severely affected preoperatively and reflects the LA "active pump" or "booster" function during the later part of the ventricular diastole, as the atrium contracts.

This atrial contraction phase depends on the LV filling pressure (LA afterload), and the $\mathrm{E} / \mathrm{E}^{\prime}$ ratio has been shown to represent a reliable index of LV filling pressure. ${ }^{21}$ The $\mathrm{E} / \mathrm{E}^{\prime}$ did not change during the postoperative period, and it was, at all times, comparable to that of the controls. This demonstrates that the improvement in LA function is not secondary to a reduction in LV filling pressure but to a "true" improvement in LA contraction, which was also confirmed by a parallel increase in the A- and $\mathrm{A}^{\prime}$-wave velocities and LA ejection fraction.

\section{Study Limitations}

Our study had some important limitations. First, the small number of patients did not allow any definite conclusions about the LA morphologic and functional improvements after minimally invasive surgery. Second, AF is also known to cause significant changes in the right atrium. However, we were not able to perform 2D-STE of the right atrium because of the small number of good-quality images 
suitable for analysis. Third, owing to the small sample size, we did not compare LA reverse remodeling and LA function between patients who had undergone LAA exclusion/ closure and those who had not. This could have incremental value in indicating the need for LAA exclusion/closure and deserves additional investigation. Fourth, we did not compare the results of minimally invasive surgery with the findings from patients converted to a sinus rhythm by medication and after catheter ablation. This will be the subject of an ongoing study. Finally, we included in the study only those patients with paroxysmal LAF who presented with minor changes in LA tissue and muscle (substrate modification) and, therefore, a lower extent of LA remodeling. Nonetheless, to accurately study LA function with the LA strain rate, it is necessary to have echocardiograms during sinus rhythm available at baseline and during follow-up. With persistent AF, it is very difficult to have periods of sinus rhythm long enough to allow a sufficient number of good-quality images for 2D-STE analysis or a sufficient number of patients. However, this limitation is shared by other recent studies in the field. ${ }^{27}$

\section{CONCLUSIONS}

Even with the study limitations, minimally invasive radiofrequency ablation resulted, in our experience, in significant LA reverse remodeling and improvement in LA compliance and LA function after restoration of sinus rhythm as demonstrated by 2D-STE analysis. Our findings need to be confirmed by additional and larger prospective studies.

We gratefully acknowledge Dr Orlando Parise for the statistical analysis and Dr James Douglas for the English revision of our report.

\section{References}

1. Vianna-Pinton R, Moreno CA, Baxter CM, Lee KS, Tsang TS, Appleton CP. Two-dimensional speckle-tracking echocardiography of the left atrium: feasibility and regional contraction and relaxation differences in normal subjects. $J \mathrm{Am}$ Soc Echocardiogr. 2009;22:299-305.

2. Saha SK, Anderson PL, Caracciolo G, Kiotsekoglou A, Wilansky S, Govind S, et al. Global left atrial strain correlates with CHADS(2) risk score in patients with atrial fibrillation. J Am Soc Echocardiogr. 2011;24:506-12.

3. Kuppahally SS, Akoum N, Burgon NS, Badger TJ, Kholmovki EG, Vijayakumar MS, et al. Left atrial strain and strain rate in patients with paroxysmal and persistent atrial fibrillation: relationship to left atrial structural remodeling detected by delayed enhancement-MRI. Circ Cardiovasc Imaging. 2010;3:231-9.

4. Chimenti C, Russo MA, Carpi A, Frustaci A. Histological substrate of human atrial fibrillation. Biomed Pharmacother. 2010;64:177-83.

5. Nguyen BL, Fishbein MC, Chen LS, Chen PS, Masroor S. Histopathological substrate for chronic atrial fibrillation in humans. Heart Rhythm. 2009;6:454-60.

6. Allessie M, Ausma J, Schotten U. Electrical, contractile and structural remodeling during atrial fibrillation. Cardiovasc Res. 2002;54:230-46.

7. Kuppahally SS, Akoum N, Badger TJ, Burgon NS, Haslam T, Kholmovski E, et al. Echocardiographic left atrial reverse remodeling after catheter ablation of atrial fibrillation is predicted by preablation delayed enhancement of left atrium by magnetic resonance imaging. Am Heart J. 2010;160:877-84.

8. Casaclang-Verzosa G, Gersh BJ, Tsang TS. Structural and functional remodeling of the left atrium: clinical and therapeutic implications for atrial fibrillation. J Am Coll Cardiol. 2008;51:1-11.
9. Tops LF, Bax JJ, Zeppenfeld K, Jongbloed MR, van der Wall EE, Schalij MJ. Effect of radiofrequency catheter ablation for atrial fibrillation on left atrial cavity size. Am J Cardiol. 2006;97:1220-2.

10. Tops LF, Delgado V, Bertini M, Marsan NA, Den Uijl DW, Trines SA, Zeppenfeld K, Holman E, Schalij MJ, Bax JJ. Left atrial strain predicts reverse remodeling after catheter ablation for atrial fibrillation. J Am Coll Cardiol. 2011;57:324-31.

11. Fuster V, Rydén LE, Cannom DS, Crijns HJ, Curtis AB, Ellenbogen KA, et al. ACC/AHA/ESC 2006 guidelines for the management of patients with atrial fibrillation: a report of the American College of Cardiology/American Heart Association Task Force on Practice Guidelines and the European Society of Cardiology Committee for Practice Guidelines (Writing Committee to Revise the 2001 Guidelines for the Management of Patients With Atrial Fibrillation). J Am Coll Cardiol. 2006;48:854-90.

12. Camm AJ, Kirchhof P, Lip GY, Schotten U, Savelieva I, Ernst S, et al. Guidelines for the management of atrial fibrillation: the Task Force for the Management of Atrial Fibrillation of the European Society of Cardiology (ESC). Europace. 2010;12:1360-420

13. Calkins H, Brugada J, Packer DL, Cappato R, Chen SA, Crijns HJ, et al. HRS/ EHRA/ECAS expert consensus statement on catheter and surgical ablation of atrial fibrillation: recommendations for personnel, policy, procedures and follow-up. Heart Rhythm. 2007;4:816-61.

14. Yilmaz A, Van Putte BP, Van Boven WJ. Completely thoracoscopic bilateral pulmonary vein isolation and left atrial appendage exclusion for atrial fibrillation. $J$ Thorac Cardiovasc Surg. 2008;136:521-2.

15. Katritsis D, Ioannidis JP, Anagnostopoulos CE, et al. Identification and catheter ablation of extracardiac and intracardiac components of ligament of Marshall tissue for treatment of paroxysmal atrial fibrillation. J Cardiovasc Electrophysiol. 2001; 12:750-8.

16. European Heart Rhythm Association; European Association for Cardio-Thoracic Surgery, Camm AJ, Kirchhof P, Lip GY, Schotten U, Savelieva I, Ernst S, Van Gelder IC, et al. Guidelines for the management of atrial fibrillation: the Task Force for the Management of Atrial Fibrillation of the European Society of Cardiology (ESC). Eur Heart J. 2010;31:2369-429.

17. Schiller NB, Shah PM, Crawford M, DeMaria A, Devereux R, Feigenbaum H, et al. Recommendations for quantitation of the left ventricle by two dimensional echocardiography. American Society of Echocardiography Committee on Standards, Subcommittee on Quantitation of Two-Dimensional Echocardiograms J Am Soc Echocardiogr. 1989;2:358-67.

18. Jiamsripong P, Honda T, Reuss CS, Hurst RT, Chaliki HP, Grill DE, et al. Three methods for evaluation of left atrial volume. Eur J Echocardiogr. 2008;9:351-5.

19. Nagueh SF, Appleton CP, Gillebert TC, Marino PN, Oh JK, Smiseth OA, et al Recommendations for the evaluation of left ventricular diastolic function by echocardiography. Eur J Echocardiogr. 2009;10:165-93.

20. Verma A, Kilicaslan F, Adams JR, Hao S, Beheiry S, Minor S, et al. Extensive ablation during pulmonary vein antrum isolation has no adverse impact on left atrial function: an echocardiography and cine computed tomography analysis. J Cardiovasc Electrophysiol. 2006;17:741-6.

21. Ommen SR, Nishimura RA, Appleton CP, Miller FA, Oh JK, Redfield MM, et al. Clinical utility of Doppler echocardiography and tissue Doppler imaging in the estimation of left ventricular filling pressures: a comparative simultaneous Doppler-catheterization study. Circulation. 2000;102:1788-94.

22. Gillinov AM, Argenziano M, Blackstone EH, Iribarne A, DeRose JJ Jr, Ailawadi G, et al. Designing comparative effectiveness trials of surgical ablation for atrial fibrillation: experience of the Cardiothoracic Surgical Trials Network. $J$ Thorac Cardiovasc Surg. 2011;142:257-64.e2.

23. Edgerton JR, Mahoney C, Mack MJ, Roper K, Herbert MA. Long-term monitoring after surgical ablation for atrial fibrillation: how much is enough? $J$ Thorac Cardiovasc Surg. 2011;142:162-5.

24. Nasso G, Bonifazi R, Del Prete A, Del Prete G, Lopriore V, Bartolomucci F, et al. Long-term results of ablation for isolated atrial fibrillation through a right minithoracotomy: toward a rational revision of treatment protocols. J Thorac Cardiovasc Surg. 2010;90:161-7.

25. Santarpino G, Rubino AS, Onorati F, Curcio A, Torella D, Tucci L, et al. Atrial fibrillation ablation induces reverse remodeling and impacts cardiac function. Minerva Cardioangiol. 2011;59:17-29.

26. Aikawa M, Watanabe H, Shimokawa T, Inoue K, Takamisawa I, Seki A, et al Preoperative left atrial emptying fraction is a powerful predictor of successful maze procedure. Circ J. 2009;73:269-73.

27. Hwang HJ, Choi EY, Rhee SJ, Joung B, Lee BH, Lee SH, et al. Left atrial strain as predictor of successful outcomes in catheter ablation for atrial fibrillation: a twodimensional myocardial imaging study. J Interv Card Electrophysiol. 2009;26:127-32. 